\title{
A national strategy for waiting-times research?
}

$\mathrm{T}$ he First Ministers' Conference on Health Care in the fall of 2004 resulted in a federal government pledge of $\$ 4.5$ billion over 6 years to reduce waiting times for cancer care, coronary angioplasty, bypass surgery and angiography, diagnostic testing (MRI and CT scans), hip and knee replacement, and cataract surgery. As part of this strategy, each province must create electronic patient registries to track waiting times. Although the immediate priority is to manage waiting lists and monitor progress in the short term, the potential to use these registries as a research tool to improve health care in the future is plain. One issue that must first be resolved is how personal patient information will be handled and protected.

Many jurisdictions already have informal waiting lists developed by individual physicians, group practices, hospital clinics and diagnostic centres. These lists vary greatly in the comprehensiveness of the clinical information contained, how the list is used, and legal provisions for access to the data for research purposes. Currently, most waiting-list registries focus on the provision of hospital services and do not collect longterm data on patient outcomes. Several Canadian provinces have waiting-list Web sites that provide information on the average interval between specialist consultation and procedure performance. Unfortunately, the data are often reported by fiscal or calendar quarters, whether rolling (always ending 3 months ago) or fixed, rather than being presented in "real time."

Waiting-list registries generally have been set up for a specific purpose (e.g., scheduling bypass surgery), and the detailed clinical information included is scant at best. Even the internationally recognized Cardiac Care Network of Ontario, which uses a consensus-driven, province-wide urgency rating to prioritize patients for cardiac procedures, contains only limited clinical data. But without comprehensive clinical data it is difficult to perform any meaningful evaluation of how well the registries are working to manage waiting lists on the basis of need.

\section{Potential applications of wait- list registries in research}

The creation of comprehensive patient registries presents us with an opportunity to create one of the world's richest data sources, one that would not only help to optimize delivery of care to patients waiting for services, but also enable us to refine our understanding of how patient outcomes relate to clinical variables. Given Canada's universal health care system, such large-scale, population-based research would be invaluable to all developed countries. Expansion of existing registries to include more detailed clinical data and contextual information would also be invaluable to research on improving future care. Some examples of the types of data that should be collected are listed in Box 1.

\section{Protecting patient information}

How should personal health information in these registries be protected, and who should be allowed access to the data? Concerns over information collected for wait-list registries being used for other purposes, such as health services or epidemiologic research, have been substantially diminished by new privacy protections established in the last decade. Yet, some privacy advocates still want full protection of individual data without regard to communal interests.

Some researchers have challenged the feasibility of ethical and legal protection of personal health information. For example, in anticipation of new Can- adian legislation, researchers involved in the Registry of the Canadian Stroke Network made determined efforts from the beginning to obtain informed consent from all stroke victims (or their surrogate decision-makers) to participate in the registry. Unfortunately, this approach resulted in a major selection bias between those who did and did not agree to participate. ${ }^{1} \mathrm{De}$ spite a significant investment of public funds (roughly \$500 000), the patients who consented to be in the registry were unrepresentative of typical stroke patients, which hindered the generalizability of the data except in certain subsets. In epidemiologic and health services research, incomplete or unrepresentative data can do greater harm than any potential compromise of the privacy of individual patients, particularly in today's context of prudent data-protection practices, mandated requirements for ethical review and strict legal requirements for the use of data in these contexts.

Generally, privacy legislation was written in an attempt to correct past wrongs, most of which were perpetrated in sectors other than health. It is now time for the legitimate health research community to begin partnering with privacy experts and advocates to look in a positive way at how personal health

Box 1: Examples of data to include in waiting-list registries

- Timeline (dates): original request for consultation with family physician (FP); appointments with FP and specialist(s); decision for service; patient departure from queue without service, or provision of the service; follow-up appointments; other relevant events

- Clinical presentation

- Symptom changes over time

- Comorbidities

- Reason(s) for delay in receiving care

- Reason for leaving queue

- Quality-of-life issues

- Long-term outcomes 
data can and should be used to better life for our population.

Is it necessary to receive consent from every patient in a registry to use his or her personal health information for research? Core ethical and privacy documents argue that if it is impracticable to obtain consent or if the risk of harm is minimal (or because legally acceptable data and privacy protections are in place), the consent requirement may be waived. ${ }^{2,3}$ Others would contend that consent in this setting can be a sham because patients may feel coerced to consent, believing that failure to do so might lower their priority in the queue.

To help obviate the need for consent, data can be anonymized and then made accessible to researchers through institutes or authorized data stewards. This strategy is certainly an alternative, but it cannot be the only solution. Some types of epidemiologic and population health studies require a capacity to link to other data sets to create, for example, longitudinal records of service provision and outcomes. This is usually accomplished through unique identifiers such as scrambled health-card numbers.

In circumstances where the public interest clearly requires it as part of an open and transparent process, governments can and do deem patient consent to be given for the use of personal information. This notion of deemed consent justifies, for example, the open transfer of patient information for quality assurance programs and to confirm the appropriateness of third-party billing. In our opinion the Canadian public, if they understood the privacy safeguards in place and the potential benefits for all, would embrace a properly regulated scheme to support research in the public interest that permits waiting-list data to be employed ethically. Health researchers need to partner with other groups, such as regulators, provincial privacy commissioners and ombudsmen, to educate the public to this vision before the opportunity is lost.

\section{Next steps}

Three things need to happen simultaneously. First, it is essential that the government and public recognize the value of wait-list registries as research tools to improve future delivery of health care. Decisions now being made about the types of clinical data to be collected will determine the future utility of these registries for research. Concerns about the use of such data must be addressed at the outset, so that personal data are well protected and important research is not hindered.

Second, Canada's federal scientific organizations, granting agencies, privacy commissioners, ombudsmen and research ethics community need to engage with one another and with politicians to resolve these issues.

Third, but of no less importance, the public should be involved in decisions about how their personal information is handled. When characterizing national values, Canadians inevitably mention our universal health care system. They characteristically have a sense of social obligation to one another, and prize efficiency and accountability. We suggest that Canadians generally would approve of data originally generated for queue management being used as well for legitimate scientific purposes in privacyprotective, ethically approved circumstances, and that re-use of data for such research should be allowed in privacy legislation and its regulations.

Failing to recognize and capitalize on this opportunity to promote the public interest through research would be irresponsible. We must give our time and attention now to this issue as an important means of promoting and protecting the health and well-being of Canadians.

\section{Pamela M. Slaughter}

Institute for Clinical Evaluative

Sciences

John Carlisle

Osgoode Hall Law School

York University

Jack Williams

Institute for Clinical Evaluative

Sciences

Lorraine E. Ferris

Faculty of Medicine

University of Toronto

Clinical Epidemiology Unit

Sunnybrook and Women's College

Health Sciences Centre

Institute for Clinical Evaluative

Sciences

Toronto, Ont.

\section{References}

1. Tu JV, Willison DJ, Silver F, Fang J, Richards JA, Laupacis A et al, for the Investigators in the Registry of the Canadian Stroke Network. Impracticability of informed consent in the registry of the Canadian Stroke Network. N Engl f Med 2004;350:1414-21.

2. Medical Research Council of Canada, Natural Sciences and Engineering Research Council of Canada, Social Sciences and Humanities Research Council of Canada. Tri-Council policy statement: ethical conduct for research involving humans, 1998 (with 2000, 2002 updates). Ottawa: Medical Research Council of Canada; 2003. Cat no MR 21-18/2003E. Available: www.pre .ethics.gc.ca/english/policystatement /policystatement.cfm (accessed 2005 Mar 14).

3. Privacy Commissioner of Canada. Annual report to Parliament 2000-2001. Ottawa: Office of the Privacy Commissioner of Canada; 2001. Cat no IP $30-1 / 2001$. 